\title{
Erratum to: Unsynchronized Nasal Intermittent Positive Pressure Ventilation to Prevent Extubation Failure in Neonates: A Randomized Controlled Trial
}

Mala Kumar • Shalini Avasthi $\cdot$ Shruti Ahuja $\cdot$

G. K. Malik • S. N. Singh

Published online: 22 September 2011

(C) Dr. K C Chaudhuri Foundation 2011

Erratum to: Indian J Pediatr (2011) 78:801-806

DOI 10.1007/s12098-010-0357-x

The original version of this article unfortunately contained a mistake.

Under Material and Methods, neonates in Group2 were given $\mathrm{O}_{2}$ by headbox on a $\mathrm{FiO}_{2}$ of 0.5 , the flow rate being $8-10 \mathrm{~L} / \mathrm{min}$ in NIPPV group and $2-3 \mathrm{~L} / \mathrm{min}$ in $\mathrm{O}_{2}$ by headbox group.

2-3 L/min should have been $5-8 \mathrm{~L} / \mathrm{min}$.

The online version of the original article can be found at http://dx.doi. org/10.1007/s12098-010-0357-x.

M. Kumar $(\varangle) \cdot$ S. Ahuja $\cdot$ G. K. Malik $\cdot$ S. N. Singh

Department of Pediatrics,

Chhatrapati Sahuji Maharaj Medical University (CSMMU),

C-83, Nirala Nagar,

Lucknow 226020, India

e-mail: mala_lko@yahoo.co.in

S. Avasthi

Department of Pediatrics, Era Medical College,

Lucknow, India 